\title{
PENGEMBANGAN JARINGAN JALAN NASIONAL DI SULAWESI UTARA DAN GORONTALO
}

\author{
Triono Junoasmono \\ Balai Pelaksanaan Jalan Nasional XV Manado \\ Kementerian Pekerjaan Umum dan \\ Perumahan Rakyat \\ Jln. Raya Manado-Bitung Km 14 \\ Manado \\ tjunoasmono@gmail.com \\ Hansen Samuel Arberto Gultom \\ Jurusan Teknik Sipil \\ Universitas Katolik Parahyangan \\ Jln. Ciumbuleuit No. 94 \\ Bandung 40141 \\ hansengultom@gmail.com
}

\author{
Brian Sixon Christian Umboh \\ Balai Pelaksanaan Jalan Nasional XV Manado \\ Kementerian Pekerjaan Umum dan \\ Perumahan Rakyat \\ Jln. Raya Manado-Bitung Km 14 \\ Manado \\ brianumboh06@gmail.com
}

\author{
Anastasia Caroline Sutandi \\ Jurusan Teknik Sipil \\ Universitas Katolik Parahyangan \\ Jln. Ciumbuleuit No. 94 \\ Bandung 4014 \\ caroline@unpar.ac.id
}

\begin{abstract}
The development of the road network is needed to determine the extent of the road network of a city or region that requires handling and development, both in the long term, medium term and short term. The purpose of this study is to obtain a master plan for the development of the national road network in North Sulawesi and Gorontalo Provinces, as a basis for planning the development of the road network for the next 5 years. The data used are primary and secondary data. Based on the results of traffic modeling, the majority of national roads in North Sulawesi Province and in Gorontalo Province have relatively small traffic volumes. The projection results, from 2020 to 2025 , show that there are 7 roads that require handling and capacity improvement.
\end{abstract}

Keywords: road network, national road, traffic modeling, road capacity, road development

\begin{abstract}
Abstrak
Pengembangan jaringan jalan diperlukan untuk mengetahui sejauh mana jaringan jalan suatu kota atau wilayah memerlukan penanganan maupun pengembangan, baik untuk jangka panjang, jangka menengah, maupun jangka pendek. Tujuan penelitian ini adalah untuk mendapatkan suatu rencana induk pengembangan jaringan jalan nasional di Provinsi Sulawesi Utara dan di Provinsi Gorontalo, sebagai basis perencanaan pengembangan jaringan jalan hingga 5 tahun yang akan datang. Data yang digunakan adalah data primer dan data sekunder. Berdasarkan hasil pemodelan lalu lintas, mayoritas jalan nasional di Provinsi Sulawesi Utara dan di Provinsi Gorontalo memiliki volume lalu lintas yang relatif kecil. Hasil proyeksi dari tahun 2020 sampai dengan tahun 2025, menunjukkan bahwa terdapat 7 ruas jalan yang memerlukan penanganan dan peningkatan kapasitas.
\end{abstract}

Kata-kata kunci: jaringan jalan, jalan nasional, pemodelan lalu lintas, kapasitas jalan, pengembangan jalan

\section{PENDAHULUAN}

Penanganan prasarana jalan merupakan suatu bentuk kepedulian terhadap pergerakan arus lalu lintas barang dan atau jasa serta manusia. Berkaitan dengan perkembangan ekonomi, penanganan prasarana jalan memiliki pengaruh yang luas, baik bagi pengguna jalan maupun bagi wilayah secara keseluruhan. Untuk itu, diperlukan kajian yang 
tepat dalam penanganan jalan, sehingga dapat mendukung pengembangan wilayah dan pertumbuhan ekonominya.

Jaringan jalan nasional di Provinsi Sulawesi Utara dan di Provinsi Gorontalo, seperti tertuang dalam Kepmen PUPR Nomor 248/KPTS/M/2015, perlu selalu disesuaikan dengan perkembangan wilayah dan kondisi ekonomi di provinsi-provinsi tersebut. Dengan demikian status jalan, baik itu merupakan jalan nasional, jalan provinsi, atau jalan kabupaten, perlu dikaji dan disesuaikan dengan kebutuhan yang ada. Selain itu, terdapat beberapa jalan nonstatus dengan kapasitas yang memenuhi syarat sebagai jalan nasional serta merupakan jalan penghubung antarjalan nasional di Provinsi Sulawesi Utara yang perlu ditingkatkan menjadi jalan nasional. Peta jaringan jalan nasional di Provinsi Sulawesi Utara dan di Provinsi Gorontalo dapat dilihat pada Gambar 1 dan Gambar 2.

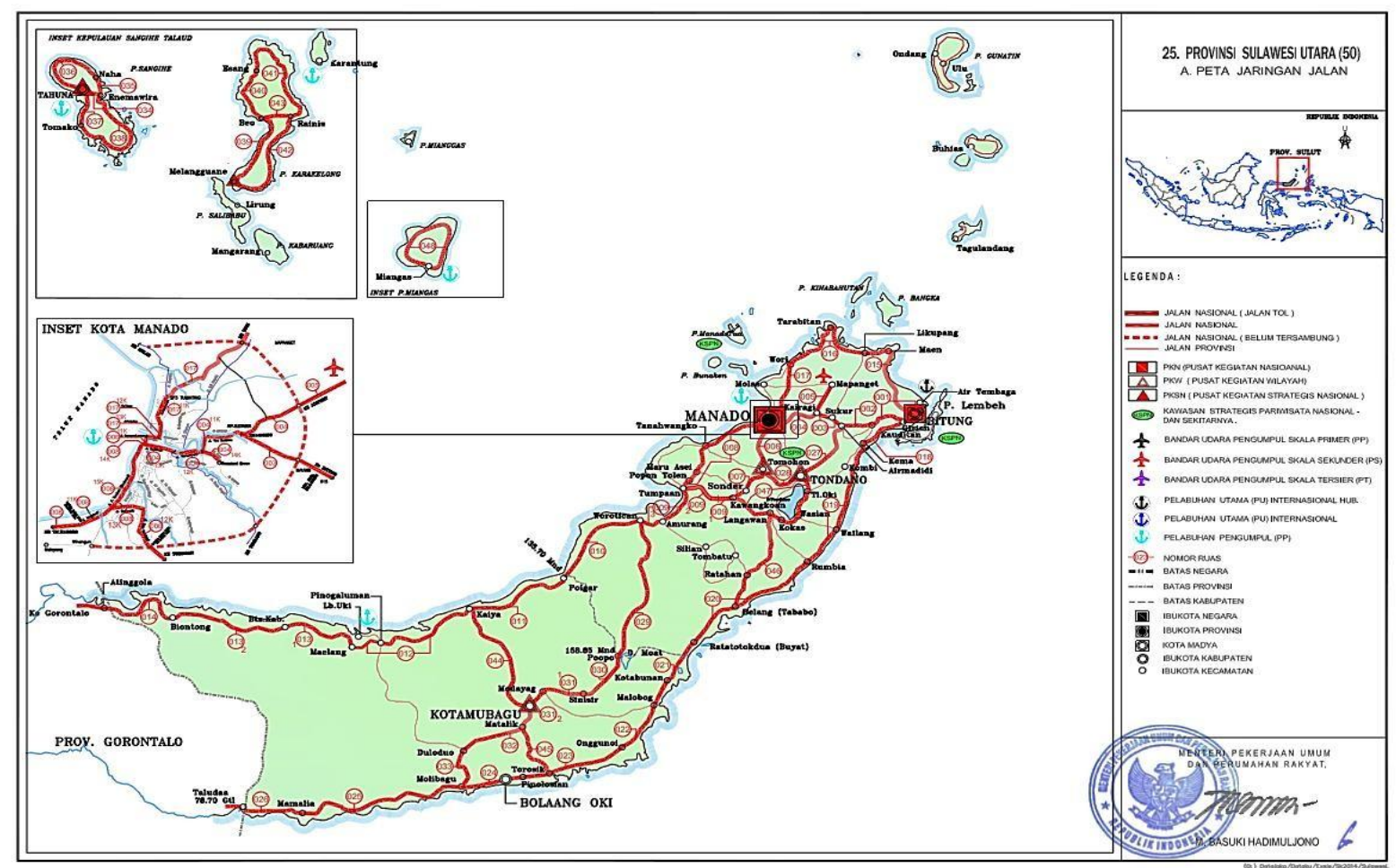

Sumber: Kementerian PUPR (2015)

Gambar 1 Peta Jaringan Jalan Nasional Provinsi Sulawesi Utara

Panjang jalan nasional di Balai Pelaksanaan Jalan Nasional XV Manado yang perlu mendapatkan perhatian dalam rencana induk jaringan jalan adalah $2.412,52 \mathrm{~km}$, dengan jumlah 126 ruas jalan, yang sesuai Kepmen PUPR Nomor 248/KPTS/M/2015 tahun 2015, dan jalan-jalan nonstatus serta jalan provinsi dan jalan kabupaten yang berada di wilayah Balai Pelaksanaan Jalan Nasional XV Manado.

Pengembangan jaringan jalan diperlukan untuk mengetahui pengaruh jaringan jalan suatu kota/wilayah yang memerlukan penanganan maupun pengembangan, karena rencana pengembangan disusun dengan menggunakan skala prioritas penanganan jaringan jalan, dalam bentuk penanganan jangka panjang, jangka menengah, maupun jangka pendek. 


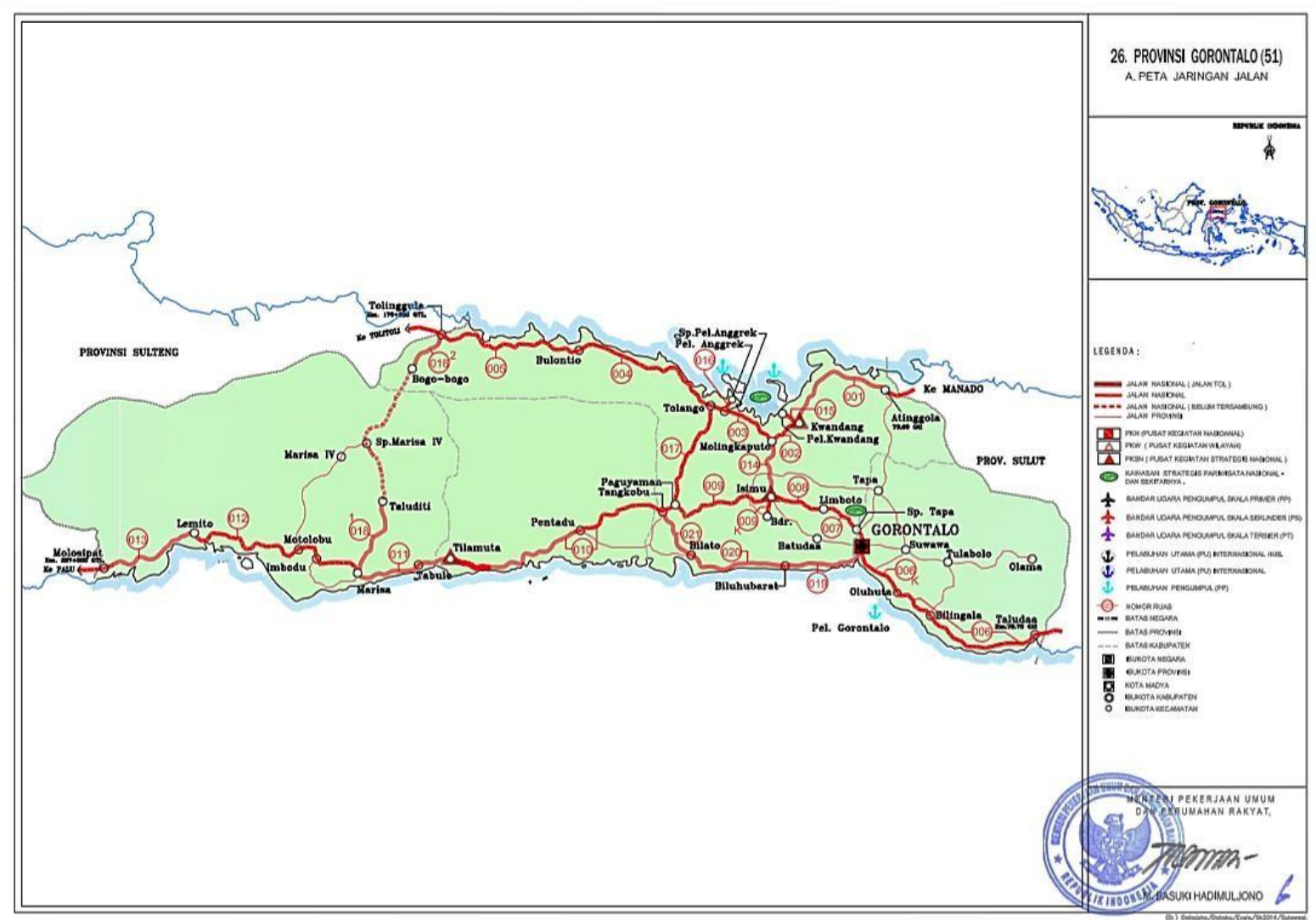

Sumber: Kementerian PUPR (2015)

Gambar 2 Peta Jaringan Jalan Nasional Provinsi Gorontalo

Dalam UU No. 38 Tahun 2004 tentang Jalan dan PP No. 34 Tahun 2006 tentang Jalan, disampaikan bahwa penyelenggaraan jalan umum dilakukan dengan mengutamakan pembangunan jaringan jalan di pusat-pusat produksi serta jalan-jalan yang menghubungkan pusat-pusat produksi dengan daerah pemasaran. Penyelenggaraan jalan umum tersebut diarahkan untuk membangun jaringan jalan dalam rangka memperkokoh kesatuan wilayah nasional sehingga menjangkau daerah terpencil.

UU No. 38 Tahun 2004 tentang Jalan juga menyebutkan klasifikasi jalan umum berdasarkan sistem, fungsi, status, dan kelas. Klasifikasi jalan umum tersebut mengatur pembagian kewenangan pembinaan jalan, sehingga jelas pihak yang bertanggung jawab dalam penyelenggaraan jalan. Bentuk kegiatan penyelenggaraan sebagaimana yang disebutkan dalam undang-undang tentang jalan tersebut meliputi pengaturan, pembinaan, pembangunan, dan pengawasan jalan.

Pengembangan jaringan transportasi perlu memperhatikan tatanan struktur tata ruang wilayah nasional, yang memuat tentang sistem kota atau permukiman dan pola jaringan transportasi. Kota memiliki 2 pengertian, yaitu: (a) kota sebagai administratif yang ditetapkan dengan suatu keputusan pemerintah; dan (b) kota sebagai fungsional yang memiliki jumlah penduduk tertentu, fasilitas pelayanan jasa, adanya kegiatan ekonomi dan sosial, serta terdapatnya kepadatan penduduk yang relatif tinggi. 
Tabel 1 Klasifikasi Jalan Umum di Indonesia

\begin{tabular}{|c|c|c|c|}
\hline No. & Pembagian & Klasifikasi & Penjelasan \\
\hline \multirow[t]{2}{*}{1} & $\begin{array}{l}\text { Menurut } \\
\text { sistem }\end{array}$ & $\begin{array}{l}\text { Sistem jaringan } \\
\text { jalan primer }\end{array}$ & $\begin{array}{l}\text { Sistem jaringan jalan dengan peranan pelayanan distribusi barang } \\
\text { dan jasa untuk pengembangan semua wilayah di tingkat nasional, } \\
\text { dengan menghubungkan semua simpul jasa distribusi yang } \\
\text { berwujud pusat kegiatan. }\end{array}$ \\
\hline & & $\begin{array}{l}\text { Sistem jaringan } \\
\text { jalan sekunder }\end{array}$ & $\begin{array}{l}\text { Sistem jaringan jalan dengan peranan pelayanan distribusi barang } \\
\text { dan jasa untuk masyarakat di dalam kawasan perkotaan. }\end{array}$ \\
\hline \multirow[t]{4}{*}{2} & $\begin{array}{l}\text { Menurut } \\
\text { fungsi }\end{array}$ & Jalan arteri & $\begin{array}{l}\text { Jalan umum yang berfungsi melayani angkutan utama dengan ciri } \\
\text { perjalanan jarak jauh, kecepatan rata-rata tinggi, dan jumlah jalan } \\
\text { masuk dibatasi secara berdaya guna. }\end{array}$ \\
\hline & & Jalan kolektor & $\begin{array}{l}\text { Jalan umum yang berfungsi melayani angkutan pengumpul atau } \\
\text { pembagi dengan ciri perjalanan jarak sedang, kecepatan rata-rata } \\
\text { sedang, dan jumlah jalan masuk dibatasi. }\end{array}$ \\
\hline & & Jalan lokal & $\begin{array}{l}\text { Jalan umum yang berfungsi melayani angkutan setempat dengan } \\
\text { ciri perjalanan jarak dekat, kecepatan rata-rata rendah, dan jumlah } \\
\text { jalan masuk tidak dibatasi. }\end{array}$ \\
\hline & & $\begin{array}{l}\text { Jalan } \\
\text { lingkungan }\end{array}$ & $\begin{array}{l}\text { Jalan umum yang berfungsi melayani angkutan lingkungan dengan } \\
\text { ciri perjalanan jarak dekat, dan kecepatan rata-rata rendah. }\end{array}$ \\
\hline \multirow[t]{5}{*}{3} & $\begin{array}{l}\text { Menurut } \\
\text { status }\end{array}$ & Jalan nasional & $\begin{array}{l}\text { Jalan arteri dan jalan kolektor dalam sistem jaringan jalan primer } \\
\text { yang menghubungkan antaribukota provinsi, dan jalan strategis } \\
\text { nasional, serta jalan tol. }\end{array}$ \\
\hline & & Jalan provinsi & $\begin{array}{l}\text { Jalan kolektor dalam sistem jaringan jalan primer yang } \\
\text { menghubungkan ibukota provinsi dengan ibukota kabupaten/kota, } \\
\text { atau antaribukota kabupaten/kota, dan jalan strategis provinsi. }\end{array}$ \\
\hline & & Jalan kabupaten & $\begin{array}{l}\text { Jalan lokal dalam sistem jaringan jalan primer yang tidak } \\
\text { termasuk jalan nasional maupun jalan provinsi, yang } \\
\text { menghubungkan ibukota kabupaten dengan ibukota kecamatan, } \\
\text { antaribukota kecamatan, ibukota kabupaten dengan pusat } \\
\text { kegiatan lokal, antarpusat kegiatan lokal, serta jalan umum dalam } \\
\text { sistem jaringan jalan sekunder dalam wilayah kabupaten, dan } \\
\text { jalan strategis kabupaten. }\end{array}$ \\
\hline & & Jalan kota & $\begin{array}{l}\text { Jalan umum dalam sistem jaringan jalan sekunder yang } \\
\text { menghubungkan antarpusat pelayanan dalam kota, } \\
\text { menghubungkan pusat pelayanan dengan persil, menghubungkan } \\
\text { antarpersil, serta menghubungkan antarpusat permukiman yang } \\
\text { berada di dalam kota. }\end{array}$ \\
\hline & & Jalan desa & $\begin{array}{l}\text { Jalan umum yang menghubungkan kawasan dan atau } \\
\text { antarpermukiman di dalam desa, serta jalan lingkungan. }\end{array}$ \\
\hline \multirow[t]{2}{*}{4} & $\begin{array}{l}\text { Menurut } \\
\text { kelas }\end{array}$ & $\begin{array}{l}\text { Jalan bebas } \\
\text { hambatan }\end{array}$ & $\begin{array}{l}\text { a. Pengaturan mengenai kelas jalan mengikuti UU No. 22/2009, } \\
\text { tentang LLAJ. }\end{array}$ \\
\hline & & & $\begin{array}{l}\text { b. Spesifikasi penyediaan prasarana jalan meliputi: } \\
\text { - Pengendalian jalan masuk } \\
\text { - Persimpangan sebidang } \\
\text { - Jumlah dan lebar lajur } \\
\text { - Ketersediaan median } \\
\text { - Pagar. }\end{array}$ \\
\hline
\end{tabular}

Sumber: Pemerintah Republik Indonesia (2004)

Persyaratan teknis jalan diatur dalam Peraturan Menteri Pekerjaan Umum No. 19/PRT/M/2011 tentang Persyaratan Teknis Jalan dan Kriteria Perencanaan Teknis Jalan. Yang dimaksud dengan persyaratan teknis jalan adalah ketentuan teknis yang harus dipenuhi oleh suatu ruas jalan agar jalan dapat berfungsi secara optimal serta memenuhi Standar Pelayanan Minimal Jalan dalam melayani lalu lintas dan angkutan jalan. Lingkup persya- 
ratan teknis jalan yang diberlakukan untuk jalan nasional, jalan provinsi, jalan kabupaten, dan jalan kota meliputi:

1) Kecepatan rencana

2) Lebar badan jalan

3) Kapasitas jalan

4) Jalan masuk

5) Persimpangan sebidang dan fasilitas berputar balik

6) Bangunan pelengkap jalan

7) Perlengkapan jalan

8) Penggunaan jalan sesuai dengan fungsinya.

Kajian mengenai Pengembangan Jaringan Jalan Nasional di Provinsi Sulawesi Utara dan di Provinsi Gorontalo ini dilakukan dengan beberapa tahapan. Tahap pertama adalah tinjauan pustaka, regulasi, dokumen perencanaan, dan studi terdahulu yang berkaitan dengan kajian pengembangan jaringan jalan. Tahap berikutnya adalah pengumpulan data sekunder ke instansi-instansi terkait di daerah dan pengumpulan data primer berupa data lalu lintas dan data inventarisasi jalan. Hasil pengumpulan data primer kemudian diolah menjadi peta jaringan jalan. Peta ini menggambarkan konektivitas jalan nasional dengan jalan-jalan lain dan pusat-pusat kegiatan yang ada di Sulawesi Utara dan Gorontalo. Peta ini juga akan menjadi informasi yang terkait dengan kebutuhan peningkatan status ruas-ruas jalan.

Peta jaringan jalan dan konektivitasnya kemudian digunakan untuk pemodelan transportasi. Data asal-tujuan dan kecepatan yang didapat dari survei primer digunakan sebagai masukan untuk perangkat lunak yang digunakan untuk memodelkan pergerakan di Sulawesi Utara dan Gorontalo. Hasil yang didapat dari model ini kemudian digunakan sebagai dasar pertimbangan prioritas pengembangan jaringan jalan nasional di Sulawesi Utara dan Gorontalo.

\section{PEMODELAN LALU LINTAS}

Kegunaan model lalu lintas adalah untuk memperlihatkan dan menjelaskan perkembangan suatu wilayah jika konsep pengembangan diterapkan. Dengan demikian dapat diketahui hal-hal yang perlu dilengkapi oleh para perencana atau pengembang dengan hanya melihat dan mempelajari model tersebut. Beberapa simulasi skenario dapat dilakukan pada model, sehingga dapat dipilih rencana pengembangan yang optimum yang sesuai dengan tujuan awal pembangunan (Tamin, 2000).

Model ini dapat digunakan untuk mencerminkan hubungan antara sistem tata guna lahan atau kegiatan dengan sistem prasarana transportasi atau jaringan transportasi, dengan menggunakan beberapa seri fungsi atau persamaan atau model matematik. Konsep pemodelan yang dapat digunakan adalah aksesibilitas, bangkitan dan tarikan pergerakan, sebaran pergerakan, pemilihan moda, pemilihan rute, serta ciri dinamis arus lalu lintas dalam sistem jaringan jalan. 


\section{Model Sistem Jaringan Jalan}

Ruas-ruas jalan yang dimasukkan ke dalam model adalah ruas-ruas yang dianggap dapat merepresentasikan kapasitas jaringan jalan wilayah kajian yang sesungguhnya dan cukup detail agar tidak terjadi pembebanan yang berlebihan pada ruas jalan tertentu serta memberikan pengaruh atau dipengaruhi oleh keberadaan jalan rencana. Berdasarkan tingkat analisis yang akan dilakukan, sistem jaringan jalan yang ditinjau pada studi ini mengikutsertakan jaringan jalan arteri primer dan jalan kolektor primer, atau dari sisi status jalan, yaitu jalan nasional dan jalan provinsi, di Sulawesi Utara dan Gorontalo. Batasan pemodelan yang dilakukan pada kajian ini adalah:

1) Menggunakan Perangkat Lunak PTV Visum 15.

2) Menggunakan zona kota/kabupaten.

3) Menggunakan data dasar Asal Tujuan Transportasi Nasional (ATTN) 2011 sebagai data bangkitan dan tarikan, dengan proyeksi pertumbuhan dan kalibrasi menggunakan pencacahan lalu lintas.

4) Menggunakan ruas-ruas jalan yang terdapat pada jaringan jalan nasional dan jalan provinsi, sesuai dengan SK Menteri PUPR No. 290 Tahun 2015, tentang SK Status Jalan.

5) Menggunakan faktor pertumbuhan sebesar $6 \%$.

Tabel 2 Zona Asal Tujuan

\begin{tabular}{lclc}
\hline \multicolumn{1}{c}{ Nama Zona } & Kode Zona & \multicolumn{1}{c}{ Nama Zona } & Kode Zona \\
\hline Bolaang Mongondow & 1 & Kota Kotamobagu & 13 \\
Bolmong Utara Selatan & 2 & Kota Manado & 14 \\
Bolmong Timur & 3 & Kota Tomohon & 15 \\
Bolmong Utara & 4 & Boalemo & 16 \\
Kepulauan Sangihe & 5 & Bone Bolango & 17 \\
Kepulauan Sitaro & 6 & Gorontalo & 18 \\
Kepulauan Talaud & 7 & Gorontalo Utara & 19 \\
Minahasa & 8 & Pahuwato & 20 \\
Minahasa Selatan & 9 & Kota Gorontalo & 21 \\
Minahasa Tenggara & 10 & Eks: Bandara Samratulangi & 22 \\
Minahasa Utara & 11 & Eks: Pelabuhan Bitung & 23 \\
Kota Bitung & 12 & Eks: Bandara Gorontalo & 24 \\
\hline
\end{tabular}

Terdapat 24 zona yang menjadi dasar pemodelan lalu lintas, dengan rincian 15 zona di Provinsi Sulawesi Utara, 6 zona di Provinsi Gorontalo, dan 3 zona pergerakan eksternal. Daftar dan kode zona yang digunakan pada pemodelan ini dapat dilihat pada Tabel 2. Data Bangkitan dan Tarikan Perjalanan menggunakan data dasar Asal Tujuan Transportasi Nasional (ATTN) 2011, yang diolah menjadi Matriks Asal Tujuan (MAT) Dasar untuk menjadi masukan pada pemodelan transportasi, yang menggunakan perangkat lunak PTV Visum 15. Hasil pemodelan pembebanan lalu lintas dengan menggunakan MAT Dasar tersebut kemudian dikalibrasi dengan menggunakan data hasil traffic counting yang telah dilakukan di Sulawesi Utara dan Gorontalo pada tahun 2018. Hasil kalibrasi dengan menggunakan data traffic counting tersebut adalah MAT Baru yang telah terkalibrasi. MAT Baru yang telah terkalibrasi dapat dilihat pada Tabel 3. 


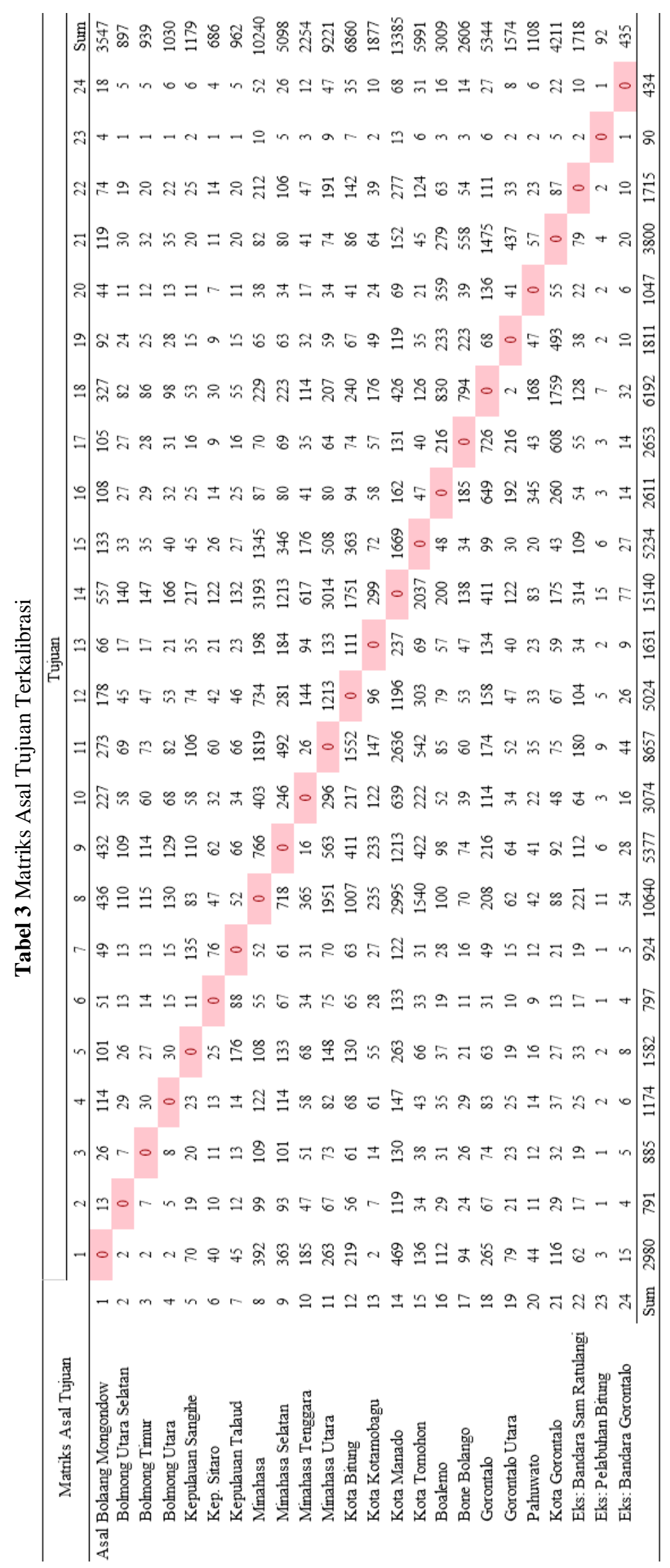




\section{Hasil Pemodelan Lalu Lintas}

Hasil dari proses pemodelan lalu lintas, dengan menggunakan perangkat lunak PTV Visum 15, dapat dilihat pada Gambar 3. Hasil model ini dapat dipahami dengan cukup mudah secara visual. Pita merah yang berada di peta ini menggambarkan adanya pergerakan dari zona-zona yang dihubungkan oleh pita tersebut. Tebalnya pita merah menggambarkan besar pergerakan yang terjadi antarzona yang dihubungkannya. Pita yang tipis, hanya berbentuk seperti garis, menggambarkan pergerakan yang tidak terlalu besar, sedangkan sebaliknya, pita yang tebal menggambarkan pergerakan yang cukup besar antara zona-zona yang dihubungkan oleh pita tersebut.

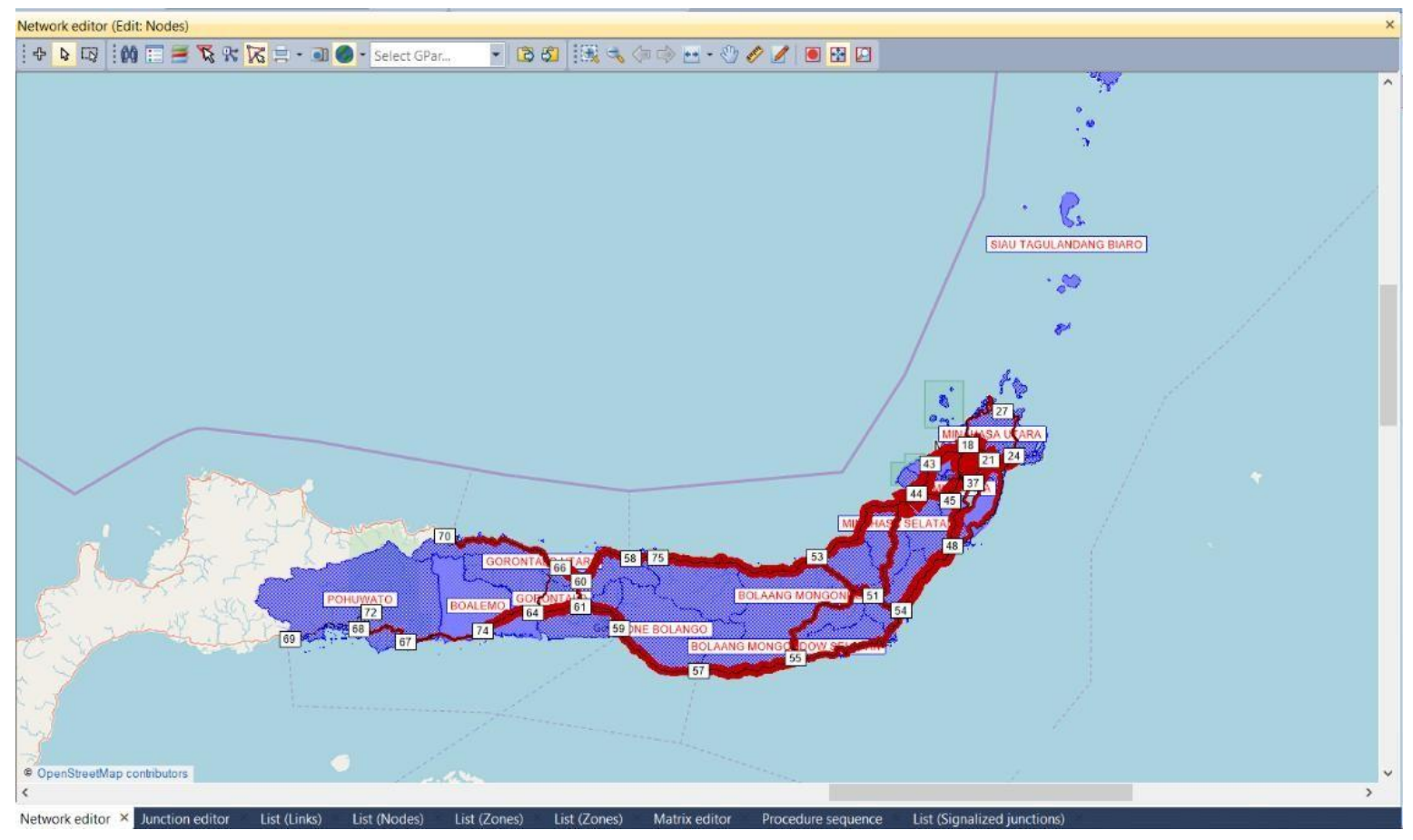

Gambar 3 Hasil Pemodelan Lalu Lintas

Setelah diperoleh hasil running pemodelan lalu lintas pada tahun dasar (2019) dengan MAT yang telah terkalibrasi, dilakukan proyeksi pemodelan lalu lintas untuk tahuntahun berikutnya. Hasil proyeksi pemodelan lalu lintas dilakukan untuk setiap tahun, mulai dari tahun dasar (2019) hingga akhir tahun rencana (2025). Hasil proyeksi pemodelan lalu lintas ini menunjukkan nilai VCR setiap ruas jalan untuk setiap tahunnya. Dari hasil proyeksi tersebut, dapat ditentukan rencana pengembangan dan penanganan. Ruas-ruas jalan yang diprediksi akan memiliki VCR lebih besar atau sama dengan 0,85 pada suatu tahun tertentu, direkomendasikan untuk dilakukan penanganan. Hasil proyeksi pemodelan lalu lintas ini dirangkum pada Tabel 4.

Hasil proyeksi dari tahun 2020 sampai dengan tahun 2025 menunjukkan bahwa terdapat 7 ruas yang harus dilakukan penanganan dan peningkatan kapasitas jalan. Ruas jalan yang pertama perlu ditingkatkan kapasitasnya adalah ruas Jalan KS Tubun pada tahun 2020, kemudian ruas Jalan Batas Kota Gorontalo-Batas Kota Limboto pada tahun 2021. Pada 
tahun 2022, ruas Jalan Batas Kota Manado-Tomohon akan memiliki VCR lebih besar daripada 0,85 sehingga kapasitasnya perlu ditingkatkan. Ruas-ruas Jalan Sam Ratulangi (Manado) dan W. Maramis (Tondano) perlu ditingkatkan pada tahun 2023. Ruas jalan berikutnya yang harus ditingkatkan kapasitasnya adalah ruas Jalan Pierre Tendean (Boulevard), pada tahun 2024, dan ruas Jalan Panjaitan (Manado), pada tahun 2025.

Tabel 4 Hasil Pemodelan Lalu Lintas untuk Ruas Jalan Nasional di Sulawesi Utara dan Gorontalo

\begin{tabular}{|c|c|c|c|c|c|c|c|c|}
\hline \multicolumn{2}{|c|}{ Nama Ruas } & $\begin{array}{l}\text { Bts. Kota } \\
\text { Manado-- } \\
\text { Tomohon }\end{array}$ & $\begin{array}{l}\text { Samratulangi } \\
\text { (Manado) }\end{array}$ & $\begin{array}{c}\text { Pierre } \\
\text { Tendean } \\
\text { (Boulevard) }\end{array}$ & $\begin{array}{c}\text { Ks. Tubun } \\
\text { (Manado) }\end{array}$ & $\begin{array}{l}\text { Panjaitan } \\
\text { (Manado) }\end{array}$ & $\begin{array}{l}\text { W. Maramis } \\
\text { (Tondano) }\end{array}$ & $\begin{array}{c}\text { Bts. Kota } \\
\text { Gorontalo- } \\
\text { Bts. Kota } \\
\text { Limboto }\end{array}$ \\
\hline \multicolumn{2}{|c|}{ Provinsi } & $\begin{array}{l}\text { Sulawesi } \\
\text { Utara }\end{array}$ & $\begin{array}{l}\text { Sulawesi } \\
\text { Utara }\end{array}$ & $\begin{array}{l}\text { Sulawesi } \\
\text { Utara }\end{array}$ & $\begin{array}{c}\text { Sulawesi } \\
\text { Utara }\end{array}$ & $\begin{array}{l}\text { Sulawesi } \\
\text { Utara }\end{array}$ & $\begin{array}{l}\text { Sulawesi } \\
\text { Utara }\end{array}$ & Gorontalo \\
\hline \multicolumn{2}{|c|}{$\begin{array}{l}\text { Kapasitas } \\
\text { (smp/jam) }\end{array}$} & 3,030 & 3,030 & 7,345 & 3,030 & 3,030 & 3,030 & 3,030 \\
\hline \multirow[t]{2}{*}{2019} & Volume & 2,214 & 2,164 & 4,780 & 2,516 & 1,800 & 2,124 & 2,328 \\
\hline & VCR & 0,73 & 0,71 & 0,65 & 0,83 & 0,59 & 0,70 & 0,77 \\
\hline \multirow[t]{2}{*}{2020} & Volume & 2,347 & 2,294 & 5,067 & 2,667 & 1,908 & 2,251 & 2,468 \\
\hline & VCR & 0,77 & 0,76 & 0,69 & 0,88 & 0,63 & 0,74 & 0,81 \\
\hline \multirow[t]{2}{*}{2021} & Volume & 2,488 & 2,431 & 5,371 & 2,827 & 2,022 & 2,387 & 2,616 \\
\hline & VCR & 0,82 & 0,80 & 0,73 & 0,93 & 0,67 & 0,79 & 0,86 \\
\hline \multirow[t]{2}{*}{2022} & Volume & 2,637 & 2,577 & 5,693 & 2,997 & 2,144 & 2,530 & 2,773 \\
\hline & VCR & 0,87 & 0,85 & 0,77 & 0,99 & 0,71 & 0,83 & 0,92 \\
\hline \multirow[t]{2}{*}{2023} & Volume & 2,795 & 2,732 & 6,035 & 3,176 & 2,272 & 2,682 & 2,939 \\
\hline & VCR & 0,92 & 0,90 & 0,82 & 1,05 & 0,75 & 0,88 & 0,97 \\
\hline \multirow[t]{2}{*}{2024} & Volume & 2,963 & 2,896 & 6,397 & 3,367 & 2,409 & 2,842 & 3,115 \\
\hline & VCR & 0,98 & 0,96 & 0,87 & 1,11 & 0,79 & 0,94 & 1,03 \\
\hline \multirow[t]{2}{*}{2025} & Volume & 3,141 & 3,070 & 6,781 & 3,569 & 2,553 & 3,013 & 3,302 \\
\hline & VCR & 1,04 & 1,01 & 0,92 & 1,18 & 0,84 & 0,99 & 1,09 \\
\hline
\end{tabular}

\section{KESIMPULAN}

Terdapat 24 zona yang menjadi dasar pemodelan lalu lintas jaringan jalan nasional di Provinsi Sulawesi Utara dan di Provinsi Gorontalo, dengan rincian 15 zona di Provinsi Sulawesi Utara, 6 zona di Provinsi Gorontalo, dan 3 buah zona pergerakan eksternal. Berdasarkan hasil pemodelan, mayoritas jalan nasional di Provinsi Sulawesi Utara dan di Provinsi Gorontalo memiliki beban lalu lintas yang masih kecil. Volume lalu lintas yang tinggi banyak ditemukan di jalan-jalan dalam kota, sedangkan volume jalan antarkota tidak terlalu besar.

Hasil proyeksi dari tahun 2020 sampai dengan tahun 2025 menunjukkan bahwa terdapat 7 ruas yang harus diberi penanganan dan peningkatan kapasitas jalan. Ruas jalan yang perlu ditingkatkan kapasitasnya adalah ruas Jalan KS Tubun, pada tahun 2020, diikuti ruas Jalan Batas Kota Gorontalo-Batas Kota Limboto, pada tahun 2021. Sedangkan pada tahun 2022, VCR ruas Jalan Batas Kota Manado-Tomohon akan berada di atas 0,85, sehingga kapasitasnya perlu ditingkatkan. Pada tahun 2023, ruas-ruas Jalan Sam Ratulangi (Manado) dan W. Maramis (Tondano) perlu untuk ditingkatkan.Selanjutnya ruas jalan yang harus ditingkatkan kapasitasnya adalah ruas Jalan Pierre Tendean (Boulevard), pada tahun 2024, dan ruas Jalan Panjaitan (Manado) pada tahun 2025. 


\section{DAFTAR PUSTAKA}

Pemerintah Republik Indonesia. 2004. Undang-Undang Nomor 38 Tahun 2004 tentang Jalan. Jakarta.

Pemerintah Republik Indonesia. 2006. Peraturan Pemerintah Republik Indonesia Nomor 34 Tahun 2006 tentang Jalan. Jakarta.

Pemerintah Republik Indonesia. 2009. Undang-Undang Nomor 22 Tahun 2009 tentang Lalu Lintas Angkutan Jalan. Jakarta.

Pemerintah Republik Indonesia. 2011. Peraturan Menteri Pekerjaan Umum dan Perumahan Rakyat No. 19/PRT/2011 tentang Persyaratan Teknis Jalan dan Kriteria Perencanaan Teknis Jalan. Jakarta.

Pemerintah Republik Indonesia. 2015. Keputusan Menteri Pekerjaan Umum dan Perumahan Rakyat No. 248/KPTS/M/2015 tentang Penetapan Ruas Jalan dalam Jaringan Jalan Primer Menurut Fungsinya sebagai Jalan Arteri (JAP) dan Jalan Kolektor 1 (JKP-1). Jakarta.

Tamin, O.Z. 2000. Perencanaan dan Permodelan Transportasi. Bandung: Penerbit ITB. 